\title{
Neurologic complications after off-pump coronary artery bypass grafting with and without aortic manipulation: Meta-analysis of 11,398 cases from 8 studies
}

\author{
Martin Misfeld, MD, PhD, ${ }^{a}$ R. John L. Brereton, FRACS, ${ }^{b}$ Elizabeth A. Sweetman, MHM, ${ }^{c}$ and \\ Gordon S. Doig, $\mathrm{PhD}^{\mathrm{c}}$
}

\begin{abstract}
Objective: Neurologic complications after coronary artery bypass grafting remain a concern. Off-pump coronary artery bypass grafting is a surgical strategy proposed to decrease this risk. Use of an off-pump anaortic technique, which leaves the ascending aorta untouched, may result in further reductions. This systematic review of all published evidence compares neurologic complications after anaortic off-pump coronary artery bypass grafting versus that with aortic manipulation.
\end{abstract}

\begin{abstract}
Methods: PubMed and Embase were searched up to August 2008. Experts were contacted, and reference lists of retrieved articles were hand searched. The search process was not limited to English-language sources. Observational studies comparing standard off-pump coronary artery bypass grafting technique with anaortic technique were eligible for inclusion if they reported neurologic complications (stroke and transient ischemic attack). Meta-analysis was conducted to assess differences between groups with regard to neurologic complications.
\end{abstract}

Results: Electronic search identified 1428 abstracts, which resulted in retrieval and detailed review of 331 fulltext articles. Eight observational studies reported neurologic complications in 5619 anaortic off-pump coronary artery bypass grafting cases and 5779 cases with aortic manipulation. Postsurgical neurologic complications were significantly lower in anaortic off-pump coronary artery bypass grafting cases (odds ratio, $0.46 ; 95 \%$ confidence interval, $\left.0.29-0.72 ; \mathrm{I}^{2}=0.8 \% ; P=.0008\right)$.

Conclusions: Avoidance of aortic manipulation during off-pump coronary artery bypass grafting decreases neurologic complications relative to standard technique in which the ascending aorta is manipulated. In patients at high risk for stroke or transient ischemic attack, we recommend avoidance of aortic manipulation during offpump coronary artery bypass grafting. (J Thorac Cardiovasc Surg 2011;142:e11-7)

\begin{abstract}
Neurologic complications after coronary artery bypass grafting $(\mathrm{CABG})$ remain among the most devastating complications. CABG performed on the beating heart with offpump techniques (OPCAB) was designed to reduce this risk. A recently published meta-analysis that compared OP$\mathrm{CAB}$ with on-pump CABG, however, did not show a significant reduction in stroke in the patients undergoing OPCAB. ${ }^{1}$ This finding is in accordance with a scientific statement of the American Heart Association in which no definitive answer could be given as to which surgical strategy is superior with regard to neurologic outcome. ${ }^{2}$
\end{abstract}

\footnotetext{
From the Department of Cardiac Surgery, ${ }^{a}$ Heart Centre Leipzig, University of Leipzig, Leipzig, Germany; and the Departments of Cardiothoracic Surgery ${ }^{\mathrm{b}}$ and Intensive Care Medicine, ${ }^{\mathrm{c}}$ Royal North Shore Hospital, Northern Clinical School, University of Sydney, Sydney, Australia.

E.A.S and G.S.D. were supported by The University of Sydney Cardiothoracic Surgery Research Grant Scheme 2009.

Disclosures: Authors have nothing to disclose with regard to commercial support.

Received for publication July 20, 2010; revisions received Oct 31, 2010; accepted for publication Nov 25, 2010; available ahead of print Jan 31, 2011.

Address for reprints: Martin Misfeld, MD, PhD, Department of Cardiac Surgery, Heart Centre Leipzig, University of Leipzig, Struempellstrasse 39, 04289 Leipzig, Germany (E-mail: martinmisfeld@yahoo.com).

$0022-5223 / \$ 36.00$

Copyright (C) 2010 by The American Association for Thoracic Surgery

doi:10.1016/j.jtcvs.2010.11.034
}

Recent evidence suggests that anaortic (or no-touch) techniques in OPCAB, in which the ascending aorta is left untouched, are able to reduce the risk of neurologic complications. ${ }^{3-5}$ The purpose of this project was to identify and synthesize the evidence reporting neurologic complications after OPCAB surgery to ascertain the baseline risk after $\mathrm{OPCAB}$ and to determine whether anaortic OPCAB provides additional risk reductions.

\section{MATERIALS AND METHODS \\ Literature Search}

MEDLINE (http://www.pubmed.org) and Embase (http://www.embase. com) were searched with appropriately broad Medical Subject Heading $(\mathrm{MeSH})$ and EMTREE terms to detect studies reporting outcomes from CABG surgery with any form of no-touch or minimal aortic manipulation procedure. All database search terms were selected to be highly sensitive. A complete list of the terms used is available in the Appendix.

We searched our own personal files and reference lists, and identified reviews were hand searched. The search was not restricted by language. The search close out date was August 2008.

\section{Study Selection}

All studies reporting patient outcomes published in any language were identified. ${ }^{6,7}$ Study selection was undertaken independently by 4 authors (M.M., R.J.L.B., E.A.S., and G.S.D). A no-touch aortic manipulation $\mathrm{CABG}$ procedure was defined as any procedure in which the ascending 


\section{Abbreviations and Acronyms \\ $\mathrm{CABG}=$ coronary artery bypass grafting \\ $\mathrm{OPCAB}=$ off-pump coronary artery bypass grafting}

aorta, aortic arch, or both as well as the supra-aortic vessels, axillary arteries, truncus brachiocephalicus, and carotid arteries, were not touched during the operation. This was considered to represent an anaortic operation.

Off-pump CABG was defined as any revascularization procedure performed on the beating heart without the use of cardiopulmonary bypass and was referred to as OPCAB. Only studies reporting stroke-related neurologic complications, such as stroke, transient ischemic attack, and (prolonged) reversible neurologic deficit, were considered for inclusion. We relied on the authors' procedures for diagnosis of these stroke-related neurologic complications.

Only methodologically sound studies that were free from major methodologic flaws were eligible (http://clinicalevidence.bmj.com/ceweb/ about/appraisal.jsp; visited March 6, 2009). Major methodologic flaws were defined a priori as excessive ( $>20 \%$ ) loss to follow-up or inappropriate crossover between groups such that a significant proportion of patients could not be analyzed according to the procedure that they were originally intended to receive.

Publications based on subgroups of patients from larger published studies were not eligible for inclusion if the parent study's patient population was already deemed eligible.

\section{Validity Appraisal}

All included studies were appraised on the reporting of 3 key methodologic criteria: (1) the objective baseline risk of stroke, (2) reporting and allocation of crossovers, and (3) the completeness of patient follow-up. Validity appraisal was undertaken independently by all authors.

\section{Outcomes}

All types of stroke were considered. In addition, clinically meaningful patient-oriented outcomes (mortality, quality of life, and physical function $)^{8}$ were also reported and assessed.

All phases of study selection, validity appraisal, and data abstraction were undertaken by all authors. At each phase, majority decisions prevailed.

\section{Statistical Analysis}

Primary analysis was conducted with a fixed effects $\operatorname{model}^{9}$ with the odds ratio metric. ${ }^{10}$ The underlying assumption behind the fixed effects model, that the true treatment effect of magnitude $(\theta)$ does not vary between studies, was assessed with a formal $\chi^{2}$ test of study $x$ treatment effect homogeneity ${ }^{9}$ and was quantified with the $\mathrm{I}^{2}$ metric. ${ }^{11}$ In the presence of important heterogeneity (heterogeneity $P<.10$ ), or if the $\mathrm{I}^{2}$ metric exceeded $50 \%,{ }^{12}$ the following a priori identified potential sources of heterogeneity were to be investigated by means stratified analysis: (1) study quality, (2) disease severity groupings, (3) intervention timing and duration, (4) concomitant interventions received, and (5) outcome measurement and timing. ${ }^{13}$ If the source of heterogeneity could not be identified, metaanalysis would not be undertaken and results from contributing trials would be presented individually.

Analysis was conducted with RevMan version 4.2 software for Windows (The Cochrane Collaboration, Oxford, UK). Two-tailed $P$ values were used to assess statistical significance or a trend toward significance.

\section{RESULTS \\ Literature Search}

The primary literature search identified 1428 abstracts. Hand review of abstracts, contact with experts, and review of reference lists resulted in the retrieval of 331 full-text articles for detailed review.

\section{Study Selection}

Details of the study selection process are presented in Figure 1. A total of 8 studies were found to meet all inclusion criteria. ${ }^{3-5,14-18}$ No on-topic studies were excluded for methodologic reasons (excessive loss to follow-up, excessive cross-overs).

\section{Included Articles}

The 8 included articles reported neurologic outcome data on 5619 patients who underwent some form of no-touch OPCAB and 5779 patients who underwent standard OPCAB with aortic manipulation. The median study size was 1437 patients, with a range from 345 to 3003 patients.

\section{Validity Appraisal}

Baseline risk factors for stroke that were found to be significantly different between study groups are reported in Table 1. No single risk factor was consistently reported across all studies such that imbalance could be controlled with multivariate or stratified analysis. Six trials did not mention patient crossovers from no-touch to standard OPCAB (or vice versa). ${ }^{4,5,14-17}$ One trial did mention crossover, but patients were analyzed in the treatment group to which they had originally been assigned. ${ }^{3}$ In another trial, $4.3 \%$ of patients in the standard OPCAB group and $4.7 \%$ of patients in the anaortic OPCAB group had conversion to on-pump CABG and were excluded from analysis. ${ }^{18}$

All studies entering the final analysis reported neurologic outcomes for all patients enrolled, either as total numbers and percentages of patients ${ }^{3-5,16-18}$ or as percentages of patients. ${ }^{14,15}$

\section{Outcomes}

The overall stroke rate among patients undergoing a notouch procedure was $0.5 \%$ (29/5619), compared with $1.4 \%$ (81/5779) among patients undergoing standard OPCAB. In the meta-analysis of all studies, the odds of stroke were significantly lower for the no-touch OPCAB group (odds ratio, $0.29 ; P=.0008 ; \mathrm{I}^{2}=0.8 \%$; Figure 2 ).

Only 6 studies reported mortality, which was variously given as operative mortality, ${ }^{4}$ in-hospital mortality, ${ }^{5}$ and 30-day mortality. ${ }^{15-18}$ Mortality was not significantly different between groups (odds ratio, 0.96; $P=0.84$; $\mathrm{I}^{2}=0$ ). No studies reported on long-term quality of life. Perioperative data were complete in all studies. 


\section{QUOROM Flow Diagram}
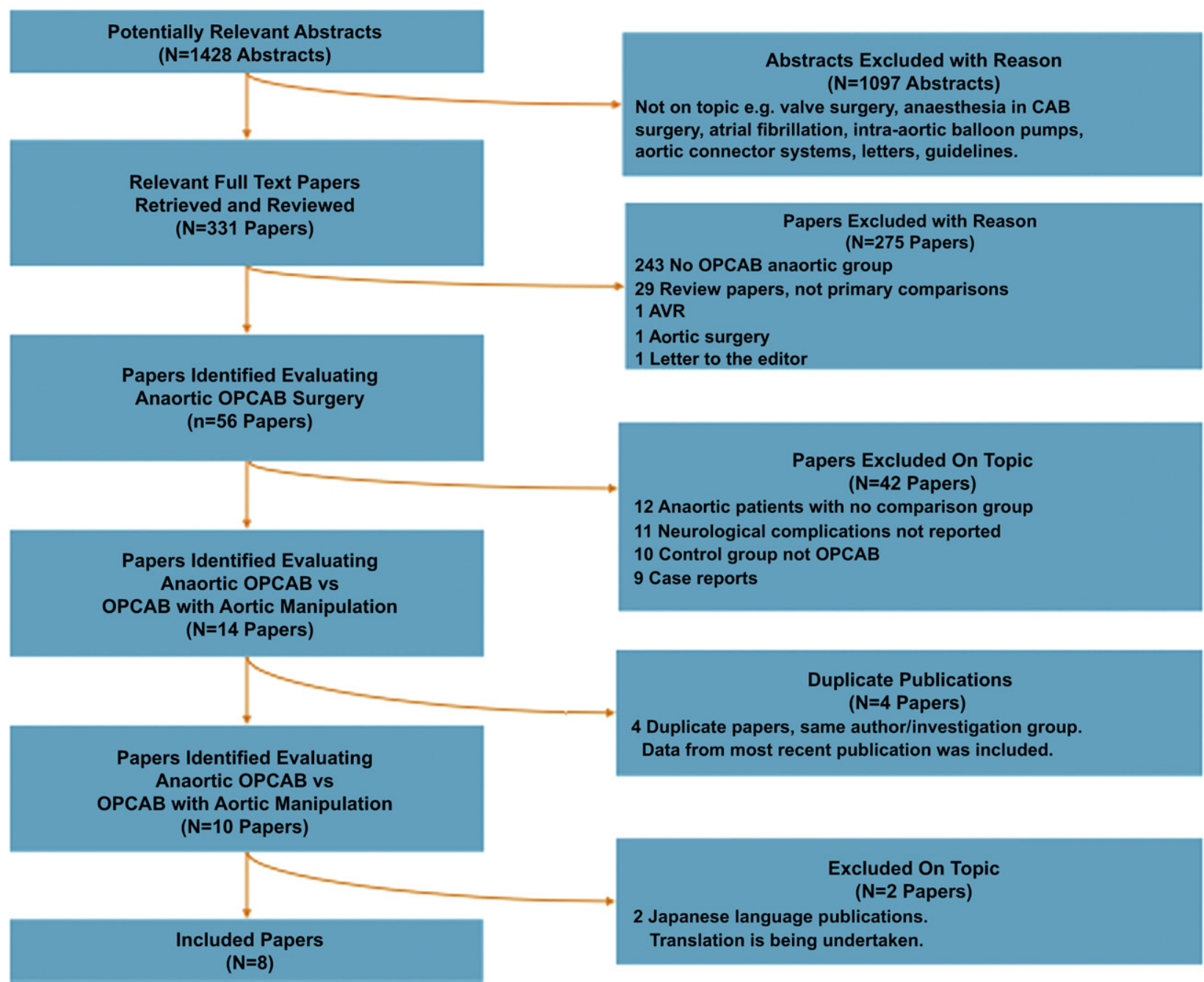

FIGURE 1. Quality of reporting of meta-analyses diagram. Identification of eligible literature. $N$ indicates number of articles or abstracts. $C A B$, Coronary artery bypass grafting; $O P C A B$, off-pump coronary artery bypass grafting; $A V R$, aortic valve replacement.

\section{Reporting Quality}

Patient age in each group was not reported by 1 trial. $^{3}$ Preoperative risk of stroke was not presented by 2 trials. ${ }^{3,14}$ There was no difference in risk of stroke between groups in 3 studies, ${ }^{4,15,17}$ whereas patients undergoing anaortic OPCAB had fewer risk factors for stroke in 2 studies ${ }^{5,16}$ and an increased risk for stroke in 1 study. ${ }^{18}$

Perioperative data were reported infrequently in all 8 studies analyzed. Preoperative carotid disease was not significantly different between groups in 4 studies, ${ }^{5,14,17,18}$ higher in the anaortic OPCAB group in 2 studies $(25.1 \%$ vs $16,35 \%, P=.04,{ }^{15}$ and $4 \%$ vs $\left.1.9 \%, P=.03^{16}\right)$, and not reported in 1 study. ${ }^{4}$ Calafiore and colleagues ${ }^{3}$ reported only the overall incidence of extracoronary vasculopathy. Preoperative atrial fibrillation was not reported in 7 studies. $^{4,5,14-18}$ One study reported that 68 patients had preoperative atrial fibrillation without any cases of postoperative stroke. ${ }^{3}$ Postoperative atrial fibrillation was not significant different in 3 studies, ${ }^{4,16,17}$ not given in 4 studies, ${ }^{3,5,14,18}$ and significantly higher $(18 \%$ vs $29 \%$, $P=.05)$ in the OPCAB group in 1 study. ${ }^{15}$

Intraoperative hypotension was not reported in 7 studies. $^{4,5,14-18}$ One study reported a $1.9 \%$ overall incidence of intraoperative low output syndrome (systolic blood pressure $<80 \mathrm{~mm} \mathrm{Hg}$ ) and a $12.2 \%$ overall incidence of stroke without reporting the incidences in each group. ${ }^{3}$

In the OPCAB group, the proximal anastomosis was performed with a side clamp in all studies. ${ }^{3-5,14-18}$ In 1 study, a modified Vettath obturator was also used to perform the proximal anastomosis in some patients. ${ }^{18}$ With regard to 
TABLE 1. Details of studies included into final analysis

\begin{tabular}{|c|c|c|c|c|c|}
\hline Study & Study period & Location & Patient age (y) & Mortality & Preoperative risk of stroke \\
\hline Calafiore $^{3}$ & 1988-2000 & Cheti, Italy & Not presented & Not presented & Not presented \\
\hline $\mathrm{Kim}^{4}$ & 1998-2001 & $\begin{array}{l}\text { Seoul, } \\
\quad \text { South Korea }\end{array}$ & $\begin{array}{c}\text { AnOPCAB mean } 61 \pm 9, \\
\text { OPCAB mean } 63 \pm 9\end{array}$ & $\begin{array}{c}\text { AnOPCAB } 0.9 \%(2 / 222), \\
\text { OPCAB } 2.4 \%(3 / 123)\end{array}$ & No difference between groups \\
\hline Patel $^{5}$ & 1997-2001 & Liverpool, UK & $\begin{array}{l}\text { AnOPCAB median } 61 \text { (55-68), } \\
\text { OPCAB median } 63 \text { (55-69) }\end{array}$ & $\begin{array}{c}\text { AnOPCAB } 1.5 \%(9 / 597), \\
\text { OPCAB } 1.0 \%(5 / 520)\end{array}$ & $\begin{array}{l}\text { Fewer current smokers } \\
\text { in AnOPCAB }(20.3 \% \text { vs } \\
30.4 \%, P<.0001)\end{array}$ \\
\hline Brucerius $^{14}$ & 1996-2001 & Leipzig, Germany & $\begin{array}{c}\text { AnOPCAB mean } 62.2 \pm 10.6 \\
\text { OPCAB mean } 64.4 \pm 10.5\end{array}$ & Not presented & Not presented \\
\hline Leacche $^{15}$ & 1996-2001 & Montreal, Canada & $\begin{array}{l}\text { AnOPCAB mean } 62 \pm 13 \\
\text { OPCAB mean } 64 \pm 10\end{array}$ & $\begin{array}{l}\text { AnOPCAB } 1.6 \%(2 / 84), \\
\text { OPCAB } 1.7 \%(9 / 556)\end{array}$ & No difference between groups \\
\hline Kapentanakis ${ }^{16}$ & 1998-2002 & Washington, DC & $\begin{array}{c}\text { AnOPCAB mean } 61.2 \pm 11.3 \\
\text { OPCAB mean } 66.2 \pm 10.7\end{array}$ & $\begin{array}{l}\text { AnOPCAB } 1.5 \%(7 / 467), \\
\text { OPCAB } 1.9 \%(48 / 2527)\end{array}$ & $\begin{array}{l}\text { Less diabetes in AnOPCAB } \\
(25 \% \text { vs } 33.6 \%, P<.0001) \text {, } \\
\text { less hypertension in } \\
\text { AnOPCAB }(62.6 \% \text { vs } \\
69.1 \%, P<.01) \text {, less carotid } \\
\text { artery disease in AnOPCAB } \\
(1.9 \% \text { vs } 4.0 \%, P=.03)\end{array}$ \\
\hline Lev-Ran $^{17}$ & $2000-2003$ & Tel Aviv, Israel & $\begin{array}{c}\text { AnOPCAB } 67.4 \pm 11.5, \\
\text { OPCAB } 68.4 \pm 10.9\end{array}$ & $\begin{array}{c}\text { AnOPCAB } 2.1 \%(9 / 429), \\
\text { OPCAB } 2.6 \%(7 / 271)\end{array}$ & No difference between groups \\
\hline Vallely $^{18}$ & 2002-2006 & Sydney, Australia & $\begin{array}{c}\text { AnOPCAB mean } 67.6(30.7-91.1), \\
\text { OPCAB mean } 67.6(22.1-90.7)\end{array}$ & $\begin{array}{c}\text { AnOPCAB } 1.4 \%(17 / 1201), \\
\text { OPCAB } 1.3 \%(7 / 557)\end{array}$ & $\begin{array}{l}\text { Greater obesity (body mass } \\
\left.\text { index }>30 \mathrm{~kg} / \mathrm{m}^{2}\right) \text { in } \\
\text { AnOPCAB }(30.2 \text { vs } 25.2 \%, \\
P=.04)\end{array}$ \\
\hline
\end{tabular}

$\overline{A n O P C A B}$, Off-pump coronary artery bypass grafting without aortic manipulation; $O P C A B$, off-pump coronary artery bypass grafting with aortic manipulation.

complete revascularization, some studies reported the mean number of distal anastomoses. This number was statistically not significant different between operative groups in 2 studies $^{15,17}$ and was significantly lower in the anaortic OPCAB group in 2 other studies $(3.2 \pm 0.9$ vs $3.5 \pm 0.8$, $P=.001^{4}$ and 2.5 vs $\left.2.6, P=.003\right) .{ }^{18}$ One study reported a significantly lower median number of distal anastomosis in the anaortic OPCAB group ( 3 vs $4, P=0.001) .{ }^{5}$ One study stated that complete revascularization was "more frequent in the OPCAB group" but without statistical significance ${ }^{15}$ Another study stated that "fewer grafts were in the anaortic OPCAB group." 16 One study compared OPCAB with minimally invasive CABG. It can be assumed that because of the limited access in minimally invasive CABG operations, the total number of distal anastomoses in that group would be smaller than that in the OPCAB group. ${ }^{14}$ The number of distal anastomoses was not given in 1 study. $^{3}$

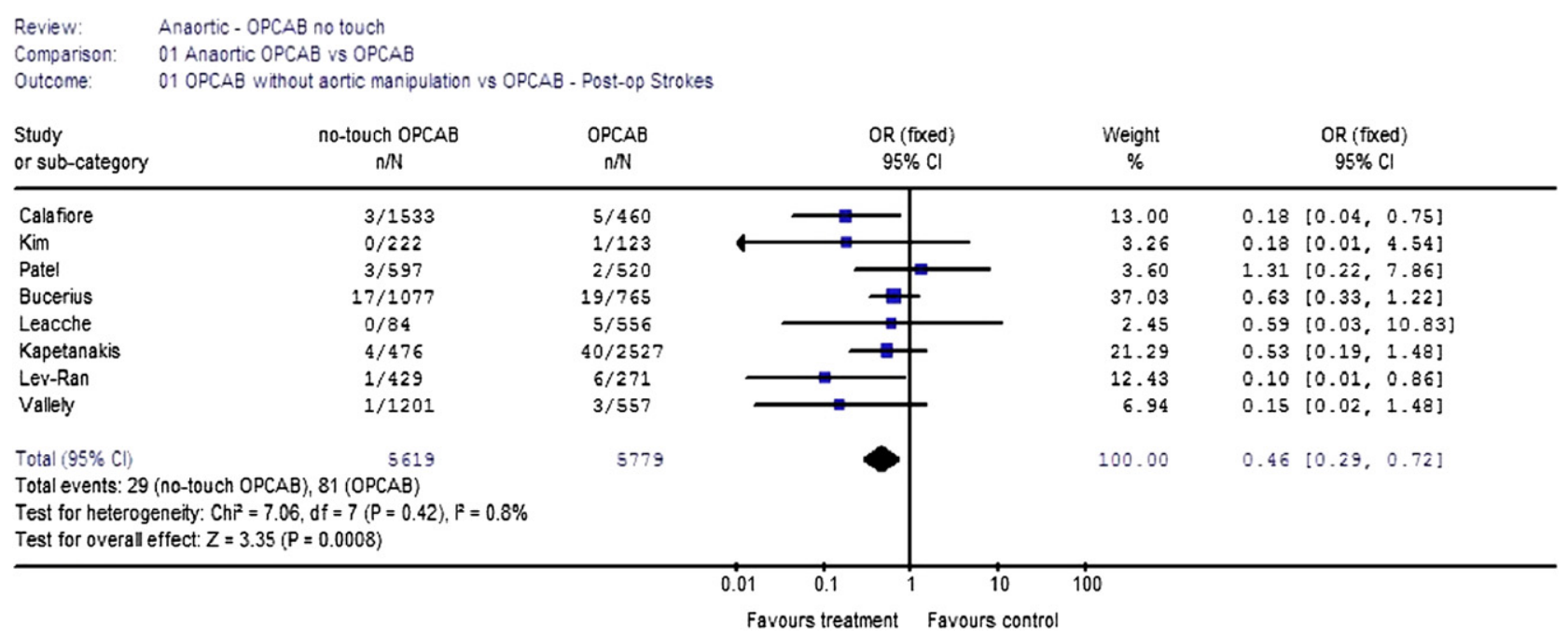

FIGURE 2. Meta-analysis of trials comparing off-pump coronary artery bypass grafting (OPCAB) with and without aortic manipulation. OR, Odds ratio; CI, confidence interval. 
TABLE 2. Perioperative patient demographic data

\begin{tabular}{|c|c|c|c|c|c|c|c|}
\hline Study & No. & Female $(\%)$ & $\begin{array}{c}\text { Preoperative ejection } \\
\text { fraction } \\
\end{array}$ & $\begin{array}{c}\text { Complete arterial } \\
\text { revascularization (\%) }\end{array}$ & $\begin{array}{l}\text { Mean } \\
\text { grafts }\end{array}$ & $\begin{array}{c}\text { Periop } \\
\text { MI (\%) }\end{array}$ & Wound infection \\
\hline \multicolumn{8}{|l|}{$\mathrm{Kim}^{4}$} \\
\hline AnOPCAB & 222 & $26.6 \%$ & $59 \% \pm 10 \%$ & $99.1 \%$ & $3.2 \pm 0.9$ & $1.4 \%$ & Mediastinitis $1.4 \%$ \\
\hline OPCAB & 123 & $33.3 \%$ & $55 \% \pm 12 \%$ & $10.6 \%$ & $3.5 \pm 0.8$ & $5.7 \%$ & Mediastinitis $0.8 \%$ \\
\hline \multicolumn{8}{|l|}{ Patel $^{5}$} \\
\hline AnOPCAB & 597 & $20.4 \%$ & $<30 \%: 7.4 \%$ & $100 \%$ & - & - & - \\
\hline OPCAB & 520 & $27.1 \%$ & $<30 \%: 5.8 \%$ & - & - & - & - \\
\hline \multicolumn{8}{|l|}{ Brucerius $^{14}$} \\
\hline AnOPCAB & 1077 & $26.7 \%$ & $57.0 \% \pm 21.1 \%$ & $100 \%$ & - & - & - \\
\hline OPCAB & 765 & $19.9 \%$ & $54.4 \% \pm 20.2 \%$ & - & - & - & - \\
\hline \multicolumn{8}{|l|}{ Leacche $^{15}$} \\
\hline AnOPCAB & 84 & $\mathrm{M} / \mathrm{F}$ ratio 5.14 & $57 \% \pm 12 \%$ & $77.3 \%$ & $2.13 \pm 0.97$ & $1.3 \%$ & - \\
\hline OPCAB & 550 & $\mathrm{M} / \mathrm{F}$ ratio 3.55 & $54 \% \pm 12 \%$ & - & $3.14 \pm 0.8$ & $1.8 \%$ & - \\
\hline \multicolumn{8}{|l|}{ Kapentanakis $^{16}$} \\
\hline AnOPCAB & 476 & $34.9 \%$ & $<35 \%: 12 \%$ & - & 2.1 & $1.1 \%$ & - \\
\hline OPCAB & 2527 & $31.4 \%$ & $<35 \%: 23.6 \%$ & - & 3.5 & $0.7 \%$ & - \\
\hline \multicolumn{8}{|l|}{ Lev-Ran ${ }^{17}$} \\
\hline AnOPCAB & 429 & $27.3 \%$ & $<35 \%: 7.7 \%$ & $100 \%$ & $2.5 \pm 0.6$ & $1.4 \%$ & $\begin{array}{l}\text { Deep } 0.9 \% \text {, } \\
\quad \text { superficial } 2.3 \%\end{array}$ \\
\hline OPCAB & 271 & $30.0 \%$ & $<35 \%: 7.7 \%$ & $100 \%$ & $2.6 \pm 0.6$ & $1.5 \%$ & $\begin{array}{l}\text { Deep } 0.4 \% \text {, } \\
\quad \text { superficial } 5.5 \%\end{array}$ \\
\hline \multicolumn{8}{|l|}{ Vallely ${ }^{18}$} \\
\hline AnOPCAB & 1201 & $24.3 \%$ & $<30 \%: 4.6 \%$ & $86.3 \%$ & $2.5 \pm 1.2$ & $0.58 \%$ & $4.33 \%$ \\
\hline OPCAB & 557 & $28.2 \%$ & $<30 \%: 4.3 \%$ & $24.4 \%$ & $2.6 \pm 0.9$ & $0.36 \%$ & $4.13 \%$ \\
\hline
\end{tabular}

Periop $M I$, Perioperative myocardial infarction; $A n O P C A B$, off-pump coronary artery bypass grafting without aortic manipulation; $O P C A B$, off-pump coronary artery bypass grafting with aortic manipulation.

With regard to operative techniques with Y-and T-grafts in the anaortic OPCAB group, the authors of the analyzed studies did not mention graft flow measurements. No postoperative angiography was routinely performed in these studies. No comment on early graft patency can therefore be made.

Additional perioperative patient demographic data are shown in Table 2. One articles ${ }^{3}$ did not present any of the data given in Table 2 because of a different focus in that study.

Duration of operation was not given in any studies analyzed. Recovery time was given as hospital stay in 5 studies. Of these, 2 did not show any difference between groups, ${ }^{17,18}$ whereas 2 showed a shorter stay in the anaortic OPCAB group $\left(5.4 \pm 2.6\right.$ vs $6.8 \pm 6.1$ days, $P=.04,{ }^{15}$ and 5 vs 4 days, $\left.P<.01^{16}\right)$. Median hospital stay was reported in 1 study (7 vs 6 days). ${ }^{5}$ Three studies did not report hospital stay at all. $3,4,14$

Timing of postoperative neurologic complications was not specifically reported in 5 studies. ${ }^{14-18}$ In the remaining studies, neurologic complications were assessed at the "time of waking up," 3 "one week postoperatively or earlier if necessary," "and "daily" with a mean period in which stroke was assessed and treated of $11.7 \pm 9.5$ days. ${ }^{5}$ No studies reported post-hospital discharge follow-up.

\section{Confirmatory Analysis}

Analysis that used the random effects model with the relative risk metric confirmed our primary analysis, which used the fixed effects model with the odds ratio metric. The results of the random effects model demonstrated a risk reduction of 0.47 in favor of the no-touch (anaortic) method $\left(P=.002, \mathrm{I}^{2}=1.4 \%\right)$.

\section{DISCUSSION}

This meta-analysis was conducted to compare the incidence of neurologic complications between patients undergoing $\mathrm{CABG}$ with anaortic $\mathrm{OPCAB}$ techniques and those undergoing $\mathrm{CABG}$ with $\mathrm{OPCAB}$ techniques including manipulation of the ascending aorta. Patients undergoing anaortic OPCAB were found to have a significantly lower postoperative incidence of neurologic complications.

Neurologic complications after CABG remain a serious problem and may be associated with increased mortality and morbidity, resulting in longer hospitalization and augmented costs. ${ }^{19}$ Innovative strategies to reduce this risk include interventional or surgical techniques such as OPCAB.

In general, OPCAB techniques have failed to show a clear benefit with regard to lessened neurologic complications relative to on-pump CABG techniques., ${ }^{1,20}$ In addition, there is a trend toward a higher incidence of stroke among patients undergoing conventional $\mathrm{CABG}$ than among those undergoing percutaneous coronary interventions. ${ }^{21,22}$ Indeed, data from the landmark report of the SYNTAX trial showed an $1.6 \%$ higher incidence of stroke in the CABG group than in the percutaneous coronary intervention 
group. ${ }^{23}$ Although the timing of follow-up in the SYNTAX trial (up to 1 year) was longer than in any studies included in this meta-analysis, 2 studies of more than 1000 anaortic OP$\mathrm{CAB}$ cases included in our analysis ${ }^{3,18}$ described a stroke rate of less than $0.3 \%$. This suggests it may be possible to lower the stroke rate with anaortic OPCAB techniques to that of the percutaneous coronary intervention group of the Syntax trial; however, longer term follow-up is needed in future studies to test this hypothesis.

With regard to CABG, it is well known that manipulation of the aorta increases the risk of neurologic complications, because atherosclerosis of the ascending aorta is the single highest risk factor for stroke. ${ }^{24}$ Innovative strategies in surgical revascularization procedures may therefore be needed to address this issue. Anaortic or no touch techniques, without manipulation of the aorta, may significantly improve neurologic outcome by avoiding maneuvers of the aorta (cannulation, crossclamping, declamping, partial clamping) that are known to cause embolism. ${ }^{25}$

With this meta-analysis, we were able to support the conclusions drawn in a few previous reports of individual studies that anaortic techniques in CABG reduce the risk of neurologic complications. ${ }^{3-5,14-18}$ Overall, 81 of 5779 patients in the OPCAB group with aortic manipulation $(1.4 \%)$ had strokes occur, compared with 29 of 5619 patients in the anaortic group $(0.4 \%)$. The extremely low measure of heterogeneity ( $\mathrm{I}^{2}$ of $0.8 \%$ ) demonstrates that the primary assumptions of the fixed effects method have been met, and-despite differences in patient selection, outcome measures and operative techniques-it is appropriate to pool studies to obtain an overall summary estimate of treatment effect attributable to the use of an anaortic OPCAB technique.

There was only 1 study $^{5}$ that appeared to show a lower rate of neurologic complications attributable to $\mathrm{OPCAB}$ surgery than in the anaortic OPCAB group, and it is important to understand that these differences were not statistically significant. Indeed, in that study only 3 of 597 patients in the anaortic group had a neurologic deficit, compared with 2 of 520 patients in the group with aortic manipulation.

Neurologic complications occurring in the anaortic OP$\mathrm{CAB}$ group may be related to hemodynamic changes during the procedure, because the heart still has to be moved during anaortic OPCAB surgery to allow visualization of the target vessel. The change in heart position also affects the aorta to some degree, which may have caused some of the neurologic complications. In addition, it is known that the cause of neurologic complications in 3\% of patients undergoing CABG who have strokes is multifactorial ${ }^{19}$ and thus may not be avoided by reducing the manipulation of the aorta alone. Aortic manipulation does, however, play a key role in the pathologic mechanism of perioperative stroke.
Furthermore, it needs to be addressed whether there is a relationship between the degree or type of aortic manipulation during $\mathrm{OPCAB}$ procedures and subsequent stroke. In theory, proximal anastomotic devices that preclude the need for a side clamp or cannulation of the aorta may be less traumatic and therefore cause fewer emboli than the use of a crossclamp or side clamp. This is of importance because for some patients with hemodynamic instability it may be necessary to perform the operation on-pump with a beating heart but still avoid the use of the side clamp for the proximal bypass graft anastomosis.

In general, only 8 studies from 331 full-text articles is a small number of studies dealing with this topic. Furthermore, most of the included trials should be considered to be methodologically weak. These findings underline the importance of performing additional studies to address this issue. We recommend that future observational studies should consider objective and repeatable diagnostic procedures for stroke and that patients should be followed-up after hospital discharge. Additionally, we believe a multicenter, prospective, randomized trial to compare anaortic OPCAB versus OPCAB with aortic manipulation with regard to neurologic and cognitive function should be undertaken.

\section{Strengths and Limitations}

We conducted an extensive and comprehensive literature search of multiple databases to identify studies published in any language. The summary estimate obtained by combining all available studies is more convincing than any single study.

If randomized, controlled trials had been conducted on this topic, our search would have identified them. No randomized, controlled trials were found.

The included articles are all low to moderate in methodologic quality and vary with regard to the completeness of reporting of key study factors, such as age and previous risk of stroke. These deficiencies do weaken our overall conclusions; however, the preponderance of the evidence still suggests benefit. It is also extremely important to note that these reporting deficiencies did not allow us to control properly for imbalance in risk factors for stroke. It is possible that patients at an overall lower risk of stroke were preferentially chosen for the no-touch anaortic procedure. Better conducted studies are clearly needed to address this question with more certainty.

Although the included studies were conducted with different assessment time periods, used different processes to select patients for each procedure, featured surgeons using slightly different techniques, and measured outcomes in different ways, the magnitude of the treatment benefit observed across the studies was remarkably consistent. Because there is no evidence of statistical heterogeneity and the magnitude of the observed treatment effect was consistent across the included studies, it is valid to obtain an 
overall summary estimate despite the apparent differences. $^{9-11}$ Indeed, the presence of this consistency of outcome benefit observed between studies suggests that the reduction in stroke may be independent of selection process, minor differences in technique, and timing of outcome assessment. This hypothesis needs to be tested in future studies.

\section{CONCLUSIONS}

The incidence of neurologic complications after CABG surgery remains a concern for clinicians and patients. This meta-analysis of all available observational studies demonstrates that relative to $\mathrm{OPCAB}$ techniques in which the aorta is touched use of an OPCAB technique that avoids manipulation of the ascending aorta may reduce stroke rate. On the basis of this best available evidence, we advocate this no-touch surgical concept.

Selection biases inherent in all observational studies cannot be overcome with more complex analysis. A welldesigned multicenter, randomized, controlled trial is required to obtain a definitive answer to this important question.

\section{References}

1. Feng ZZ, Shi J, Zhao XW, Xu ZF. Meta-analysis of on-pump and off-pump coronary arterial revascularization. Ann Thorac Surg. 2009;87:757-65.

2. Sellke FW, DiMaio JM, Caplan LR, Ferguson TB, Gardner TJ, Hiratzka LF, et al. Comparing on-pump and off-pump coronary artery bypass grafting: numerous studies but few conclusions: a scientific statement from the American Heart Association council on cardiovascular surgery and anesthesia in collaboration with the interdisciplinary working group on quality of care and outcomes research. Circulation. 2005; 111:2858-64.

3. Calafiore AM, Di Mauro M, Teodori G, Di Giammarco G, Cirmeni S, Contini M, et al. Impact of aortic manipulation on Incidence of cerebrovascular accidents after surgical myocardial revascularization. Ann Thorac Surg. 2002;73:1387-93.

4. Kim KB, Kang CH, Chang W-I, Lim C, Kim JH, Ham BM, et al. Off-pump coronary artery bypass with complete avoidance of aortic manipulation. Ann Thorac Surg. 2002;74:S1377-82.

5. Patel NC, Deodhar AP, Grayson AD, Pullan DM, Keenan DJM, Hasan R, et al. Neurological outcomes in coronary surgery: independent effect of avoiding cardiopulmonary bypass. Ann Thorac Surg. 2002;74:400-6.

6. Egger M, Juni P, Bartlett C, Holenstein F, Sterne J. How important are comprehensive literature searches and the assessment of trial quality in systematic reviews? Empirical study. Health Technol Assess. 2003;7:1-76.

7. Jüni P, Holenstein F, Sterne J, Bartlett C, Egger M. Direction and impact of language bias in meta-analyses of controlled trials: empirical study. Int J Epidemiol. 2002;31:115-23.

8. Prentice RL. Surrogate endpoints in clinical trials: definition and operational criteria. Stat Med. 1989;8:431-40.

9. Villar J, Mackey ME, Carroli G, Donner A. Meta-analyses in systematic reviews of randomized controlled trials in perinatal medicine: comparison of fixed and random effects models. Stat Med. 2001;20:3635-47.

10. Deeks JJ. Issues in the selection of a summary statistic for meta-analysis of clinical trials with binary outcomes. Stat Med. 2002;21:1575-600.

11. Higgins JP, Thompson SG. Quantifying heterogeneity in a meta-analysis. Stat Med. 2002;21:1539-58.

12. Hatala R, Keitz S, Wyer P, Guyatt G, Evidence-Based Medicine Teaching Tips Working Group. Tips for learners of evidence-based medicine: 4. Assessing heterogeneity of primary studies in systematic reviews and whether to combine their results. CMAJ. 2005;172:661-5.
13. Glasziou PP, Sanders SL. Investigating causes of heterogeneity in systematic reviews. Stat Med. 2002;21:1503-11.

14. Bucerius J, Gummert JF, Borger MA, Walther T, Doll N, Onnasch JF, et al. Stroke after cardiac surgery: a risk factor analysis of 16,184 consecutive adult patients. Ann Thorac Surg. 2003;75:472-8.

15. Leacche M, Carrier M, Bouchard D, Pellerin M, Perrault LP, Pagá P, et al. Improving neurologic outcome in off-pump surgery: the "no touch" technique. Heart Surg Forum. 2003;6:169-75.

16. Kapetanakis EI, Stamou SC, Dullum MK, Hill PC, Haile E, Boyce SW, et al. The impact of aortic manipulation on neurologic outcomes after coronary artery bypass surgery: a risk-adjusted study. Ann Thorac Surg. 2004;78:1564-71.

17. Lev-Ran O, Braunstein R, Sharony R, Kramer A, Paz Y, Mohr R, et al. No-touch aorta off-pump coronary surgery: the effect on stroke. J Thorac Cardiovasc Surg. 2005;129:307-13.

18. Vallely MP, Potger K, McMillan D, Hemli JM, Brady PW, Brereton RJ, et al Anaortic techniques reduce neurological morbidity after off-pump coronary artery bypass surgery. Heart Lung Circ. 2008;17:299-304.

19. Roach GW, Kanchuger M, Mangano CM, Newman M, Nussmeier N, Wolman R, et al. Adverse cerebral outcomes after coronary bypass surgery. Multicenter study of Perioperative Ischemia Research Group and the Ischemia Research and Education Foundation Investigators. N Engl J Med. 1996;335: 1857-63.

20. Chu D, Bakaeen FG, Dao TK, LeMaire SA, Coselli JS, Huh J. On-pump versus off-pump coronary artery bypass grafting in a cohort of 63,000 patients. Ann Thorac Surg. 2009;87:1820-7.

21. Bravata DM, Gienger AL, McDonald KM, Sundaram V, Perez MV, Varghese R, et al. Systematic review: the comparative effectiveness of percutaneous coronary artery interventions and coronary artery bypass graft surgery. Ann Intern Med. 2007; 147:703-16.

22. Li Y, Zheng Z, Xu B, Zhang S, Li W, Gao R, et al. Comparison of drug-eluting stents and coronary artery bypass surgery for the treatment of multivessel coronary disease: three-year follow-up results from a single institution. Circulation. 2009;119:2040-50.

23. Serruys PW, Morice MC, Kappetein AP, Colombo A, Holmes DR, Mack MJ, et al. Percutaneous coronary intervention versus coronary artery bypass grafting for severe coronary artery disease. $N$ Engl J Med. 2009;360:961-72.

24. Bergman P, van der Linden J. Atherosclerosis of the ascending aorta as a major determinant of the outcome of cardiac surgery. Nat Clin Pract Cardiovasc Med. 2005;2:246-51.

25. Stump DA, Rogers AT, Hammon JW, Newman SP. Cerebral emboli and cognitive outcome after cardiac surgery. J Cardiovascular Vasc Anesth. 1996;10:113-9.

\section{APPENDIX. PubMed (MeSH) Terms}

PubMed search was as follows: (stroke or "cerebrovascular disorders" or CVA or "cerebral vascular" or "cerebral bleed" or neurologic or cerebrovascular) AND ("coronary artery bypass" or "coronary artery bypass, off pump" or "coronary artery surgery" or OPCAB or CABG) AND (aorta or aortic or aortic no touch or anaortic or "no cannulation")

\section{Embase (EMTREE) Terms}

Embase search was as follows: ("Cerebrovascular disease" or stroke or "cerebrovascular accident" or "cerebrovascular malformation" or "neurologic disease") AND ("Coronary artery bypass graft" or "coronary artery surgery" or " coronary artery bypass surgery" or "heart surgery") AND ("aorta":ti,ab or "aortic":ti,ab or "anaortic":ti,ab or "no touch":ti,ab or "no cannulation":ti,ab) 